\title{
Randomized clinical trial comparing ceftiofur hydrochloride with a positive control protocol for intramammary treatment of nonsevere clinical mastitis in dairy cows
}

\author{
Cristina Simões Cortinhas, ${ }^{*}$ Tiago Tomazi, ${ }^{*}$ Mário Sérgio Ferreira Zoni, $†$ Elio Moro,ł \\ and Marcos Veiga dos Santos*1 \\ *Department of Animal Nutrition and Production, School of Veterinary Medicine and Animal Science, University of São Paulo, \\ Pirassununga 13635-900, São Paulo, Brazil \\ †Department of Agricultural Sciences, Federal University of Paraná, Curitiba 80060-000, Paraná, Brazil \\ $\ddagger Z o e t i s$ Animal Health, São Paulo 04709-111, São Paulo, Brazil
}

ABSTRACT

The objective of this study was to compare ceftiofur hydrochloride with a positive control protocol for intramammary treatment of nonsevere clinical mastitis in dairy cows. A total of 264 clinical mastitis cases on 11 commercial dairy farms were treated with intramammary infusions, once a day for $4 \mathrm{~d}$ using 1 of 2 treatments: (1) ceftiofur hydrochloride $125 \mathrm{mg}$; or (2) control: tetracycline $200 \mathrm{mg}+$ neomycin $250 \mathrm{mg}+$ bacitracin 28 $\mathrm{mg}+$ prednisolone $10 \mathrm{mg}$. Streptococcus agalactiae was the most frequently isolated gram-positive pathogen from clinical mastitis, followed by Staphylococcus aureus. Klebsiella spp. and Escherichia coli were the most isolated gram-negative bacteria from clinical mastitis. No significant differences were observed between treatments regarding the overall clinical cure, bacteriological cure, and new infection. No effect of treatment regimen was observed when the bacterial group (gram-positive vs. gram-negative) was evaluated. The overall clinical cure was 0.79 for ceftiofur-treated cows and 0.74 for control-treated cows, whereas the overall bacteriological cure was 0.79 for ceftiofur-treated cows and 0.76 for control-treated cows. Furthermore, the new intramammary infection was 0.10 for cows treated with ceftiofur and 0.11 for cows treated with control. In conclusion, the use of intramammary ceftiofur hydrochloride for treatment of nonsevere clinical mastitis has similar efficacy as a treatment regimen with a combination of antimicrobial agents (tetracycline + neomycin + bacitracin).

Key words: clinical mastitis therapy, ceftiofur hydrochloride, clinical and bacteriological cure

\footnotetext{
Received January 13, 2016.

Accepted March 8, 2016.

${ }^{1}$ Corresponding author: mveiga@usp.br
}

\section{INTRODUCTION}

Bovine mastitis is one of the main diseases that negatively affect dairy industry profitability, as it reduces the milk quality and cow productivity, and generates costs due to milk discard, cows culling, increased labor and treatment costs (Halasa et al., 2007; Heikkilä et al., 2012). The imprudent use of antibiotics for treatment of bovine mastitis has been considered a risk factor for the increased resistance to antimicrobials used both in humans and in veterinary medicine (Oliver and Murinda, 2012). In addition, mastitis may also be associated with human food safety due to the increased risks of both microbiological pathogens, especially through consumption of unpasteurized dairy products, and antimicrobial residue concerns (Lago et al., 2011). Thus, the development of efficient therapeutic strategies for mastitis treatment has been a dairy industry goal (Gruet et al., 2001).

Antimicrobial therapy remains the main treatment strategy for IMI, and several antimicrobial formulations are commercially available (Roberson, 2012). Since ceftiofur has been marketed to be administered by the intramammary route, this antibiotic has been used extensively for treatment of clinical mastitis (CM) in dairy cattle (Oliveira and Ruegg, 2014; Ruegg et al., 2015). Ceftiofur is a third-generation cephalosporin with broad-spectrum effectiveness against both grampositive and gram-negative pathogens (Roberson, 2012). Previous studies have evaluated the efficacy of intramammary ceftiofur treatment by varying the duration of therapy (Truchetti et al., 2014), or by comparison with different generations of cephalosporins (Schukken et al., 2013), or with a negative-control (Schukken et al., 2011). However, no study has compared ceftiofur intramammary therapy with another broad-spectrum treatment regimen with a combination of active ingredients. In the present study, we used as a positive control an approved intramammary product with broad spectrum, 
comprising a combination of tetracycline + neomycin + bacitracin. Studies comparing antibiotics commercially available and routinely used in dairy herds can generate more relevant results in the day-to-day decision-making regarding the treatment of $\mathrm{CM}$.

The objective of this study was to compare the efficacy of intramammary ceftiofur hydrochloride therapy with a positive control formulation consisting of a combination of antimicrobials for treatment of bovine nonsevere CM.

\section{MATERIALS AND METHODS}

\section{Study Design}

The study design used a multi-centered, randomized positive controlled field trial. Lactating cows from 11 different dairy herds were randomly assigned to be treated with 1 of 2 commercial intramammary antimicrobials (ceftiofur $125 \mathrm{mg}$, or tetracycline $200 \mathrm{mg}+$ neomycin $250 \mathrm{mg}+$ bacitracin $28 \mathrm{mg}+$ prednisolone $10 \mathrm{mg})$.

\section{Selection of Dairy Herds}

A total of 11 Brazilian commercial dairy herds located in States of São Paulo $(\mathrm{n}=2)$, Minas Gerais $(\mathrm{n}=2)$, and Parana $(\mathrm{n}=7)$ were selected based on interest in participating in the study, and availability of accurate records of CM cases. Herds should have easily identifiable cows with ear tags, but no specific animal management or housing, bulk milk SCC, or CM incidence was required for inclusion of herds in the study.

\section{Herd Details}

Information about herd size (number of lactating dairy cows), herd management (housing, bedding, feeding), and udder health management (CM detection, pre- and postteat disinfection, dry cow therapy) were recorded. The herd size ranged from 130 to 2,100 lactating cows (average $533.3 \pm 573.2$ lactating cows/herd). All dairy farms housed cows in freestall barns, and cows were milked twice a day in 2 herds and 3 times per day in 9 herds. The average annual milk yield/cow per day was $29.5 \pm 5.3 \mathrm{~kg}$ (minimum $=23 \mathrm{~kg}$; maximum $=38$ $\mathrm{kg}$ ). The average herd bulk milk SCC per month ranged between 190 and $700 \times 10^{3}$ cells/mL during the study period. Milking routine was similar between farms. Preand postmilking teat disinfection and detection of CM based on visual observation of first strips of milk were practiced in all farms. Milking procedures and equipment did not change during the study period. All 11 farms used blanket dry cow therapy by intramammary infusion of antimicrobials at drying off.

\section{Inclusion Criteria for Cows}

Lactating dairy cows presenting CM were eligible for the study when (1) they were in good general health, (2) had 4 functional quarters, (3) had not experienced $\mathrm{CM}$ in the last $30 \mathrm{~d}$, and (4) had not received treatment with antibiotics for another disease in the last $30 \mathrm{~d}$. Clinical mastitis was defined as a quarter with abnormal milk, accompanied or not by other clinical signs, such as udder swelling, redness, heat, and pain (IDF, 1999) or associated general clinical symptoms.

Before treatment, each enrolled cow was examined clinically by trained farm personnel and the results recorded. Farm personnel were trained to classify CM severity according to Wenz et al. (2006) in 3 scores (mild, moderate, and severe). Mild CM was assigned when milk had changes in appearance, such as abnormal viscosity, color, or consistency (presence of flakes or clots), but no other local (udder swelling) or systemic signs. Moderate CM was assigned when milk had abnormal appearance and udder swelling or firmness, but no systemic signs. Severe CM was assigned when the cow had both local and systemic signs, such as lack of appetite, depressed rumen function, or body temperature $>39.2^{\circ} \mathrm{C}$. Only cows with $\mathrm{CM}$ in only one quarter and that were not classified as severe were included in this study.

Exclusion criteria for cows were (1) visible lesions on the udder, teat, or teat orifice; (2) CM occurring less than $30 \mathrm{~d}$ from expected day of drying-off; and (3) cows with average milk yield $<5 \mathrm{~kg} / \mathrm{d}$ at the test day before the occurrence of CM case. Before inclusion in the study, information about cows, such as breed, date of birth, number of lactations, date of last calving, milk yield at time of treatment, cow SCC, and history of previous mastitis cases were recorded.

\section{Postadmission Exclusion}

Cows were excluded after enrolment in the study when the pretreatment milk sample was contaminated ( $>2$ bacteria species isolated) and when cows experienced concomitant diseases other than the first CM case, which included CM in another quarter or other diseases that required antibiotic or anti-inflammatory treatment. Clinical cases in which yeasts were isolated in the pretreatment milk samples were not included in the statistical analysis because the protocols evaluated in our study were not expected to be efficacious against these microorganisms. Nevertheless, as the result of 
culture was not available at the moment of CM diagnosis, cows with isolation of yeast in the pretreatment milk samples were treated with one of the protocols evaluated in this study.

\section{Treatment Protocols and Randomization}

Intramammary treatments were administered by trained farm personnel. Cows were randomly assigned to either one of the treatment protocols according to a previous created randomization list of cows per treatment for each farm. Mild clinical cases were treated with intramammary infusions, once a day for $4 \mathrm{~d}$ using 1 of 2 treatments: (1) ceftiofur hydrochloride $125 \mathrm{mg}$ (Spectramast LC, Zoetis, São Paulo, Brazil); or (2) control: tetracycline $200 \mathrm{mg}+$ neomycin $250 \mathrm{mg}+$ bacitracin $28 \mathrm{mg}+$ prednisolone $10 \mathrm{mg}$ (Mastijet Forte, MSD Animal Health, São Paulo, Brazil). Cows with moderate severity score were treated using the same protocol used for mild cases, but cows of the ceftiofur group received an intramuscular injection of $5 \mathrm{mg}$ of flumethasone (Flucortan, Zoetis, São Paulo, Brazil) at a 24-h interval, during the first $2 \mathrm{~d}$ of the treatment protocol. Severe cases of CM were treated using specific farm protocol and were not included in this study.

\section{Milk Sampling}

Sampling and clinical data collections were done by farm personnel (at the onset of the clinical case) or by a local investigator. Farm personnel were trained for CM detection, severity score classification, and milk sampling before the onset of the study. Farms were visited twice a week for data recording and for milk sample collection for microbiological culture.

At the time a cow was diagnosed with $\mathrm{CM}$, she was enrolled in this study and a milk sample was collected from the infected quarter for microbiological culture. All cows diagnosed with CM were sampled, but only those that met the eligibility criteria were evaluated in the further analysis. After the treatment protocols, milk samples were again collected from the treated quarter at $14 \pm 3$ and $21 \pm 3 \mathrm{~d}$ after the onset of treatment. For milk sampling, the teat end of the affected quarter was carefully disinfected and 3 streams of milk were discarded. All collected milk samples were immediately placed on ice and stored in on-farm freezers for less than 2 wk before microbiological culture.

\section{Bacteriological Identification}

Bacteriological culture was performed according to National Mastitis Council standards (Oliver et al., 2004b). Briefly, from each sample, $0.01 \mathrm{~mL}$ of milk was plated on blood agar and incubated aerobically for 24 and $48 \mathrm{~h}$ at $37^{\circ} \mathrm{C}$. A quarter was considered culture-positive when growth of at least one colony was detected on streaks. Samples yielding more than 2 different bacterial species were considered contaminated and removed from the statistical analysis. Bacteria were identified based on colony morphology and Gram staining. For gram-positive cocci, catalase tests with hydrogen peroxide $(3 \%)$ were used to differentiate between catalase-positive staphylococci and catalase-negative cocci. Coagulase test was performed using sterile rabbit plasma to distinguish Staphylococcus aureus (coagulase-positive) from non-Staph. aureus staphylococci, referred to as CNS. Streptococci were subdivided into esculin-positive cocci (Strep. uberis and Streptococcus spp.) and esculin-negative cocci (Strep. agalactiae and Strep. dysgalactiae, respectively). Christie, Atkins, Munch-Petersen test was used to differentiate Strep. agalactiae from Strep. dysgalactiae. Bile esculin test and the pyrrolidonyl arylamidase test (Probac do Brasil, São Paulo, Brazil) were used to differentiate isolates as Streptococcus spp., Streptococcus uberis, or Enterococcus spp. gram-negative organisms were identified by colony morphology on MacConkey's agar, and by evaluation of the following biochemical characteristics: sucrose and glucose fermentation, hydrolysis of urea, gas production, motility capacity, indole production, $\mathrm{H}_{2} \mathrm{~S}$ production, L-tryptophan deaminase, and lysine reaction.

\section{Assessment of Treatment Outcome}

The primary outcomes of the treatment were bacteriological and clinical cure. A quarter was defined as bacteriologically cured when it was infected at the start of treatment with one microorganism, but the same microorganism was not present in any of the 2 posttreatment samples. A quarter was defined as clinically cured when it had the presence of normal milk and a normal gland, evaluated at the end of the treatment (d 4) and on the 2 posttreatment evaluation days (14 \pm 3 and $21 \pm 3 \mathrm{~d}$ after the onset of treatment).

If no posttreatment samples were taken for reasons other than insufficient progress (such as missing sample), the case was not eligible for bacteriological cure evaluation, but could still be considered for evaluation of clinical cure. If a cow was removed from the trial during the follow-up period due to insufficient progress, the case was considered a failure of both bacteriological and clinical cure. A new infection was considered as the presence of a microorganism other than any microorganism isolated pretreatment, in 1 or 2 of the posttreatment samples. 


\section{Statistical Analysis}

The required sample size was estimated to be 242 (n $=121$ clinical cases per treatment group) based on a 2 -sided $\chi^{2}$ test, with significance level at 0.05 and power of 0.8 , assuming that differences of bacteriological cure of treatment protocols are less than $15 \%$ (ceftiofur: 0.7 and positive control: 0.55 ). To allow cows that were culture negative at first CM diagnosis and excluded cases, the objective of the study was to enroll a minimum of 350 clinical cases. However, after cow enrollment, a large proportion of the cows were excluded (Figure 1), and the power of the study to detect at least a $15 \%$ difference in the bacteriological cure was $0.51(\mathrm{n}=53$ for the ceftiofur and 56 for the control protocols).

The mammary quarter with CM was considered the experimental unit. The assumptions of normality and homogeneity of variance of the models were assessed using the Kolmogorov-Smirnov test with the PROC Univariate command of SAS version 9.2 (SAS Institute Inc., Cary, NC) and scatter plots of the model residuals. To evaluate the homogeneity of data between the 2 treatment groups, normally distributed continuous data were tested statistically using Student's $t$-test, and nominal data (i.e., clinical scores), were compared as proportions with a $\chi^{2}$-test.

Bacteriological and clinical cure, and proportion of new IMI were evaluated using mixed model logistic regression analysis, where number of lactations, number of clinical cases before treatment, quarter position (front/ hind), pretreatment linear score of SCC (measured at the most recent milk recording before CM occurrence), clinical severity score, and DIM were included as fixed effects, and herd was included as a random effect. The first logistic regression model (model 1) used for the evaluation of clinical and bacteriological clinical cure, and risk of new intramammary infection, was

$$
\begin{gathered}
\text { logit }(\text { cure; NIMI })=\text { intercept } \\
+ \text { parity }+ \text { DIM }+ \text { quarter position } \\
+ \text { number of clinical cases before treatment } \\
+\operatorname{lnSCC}+\text { severity score }+ \text { treatment } \\
+ \text { herd (random) } ;
\end{gathered}
$$

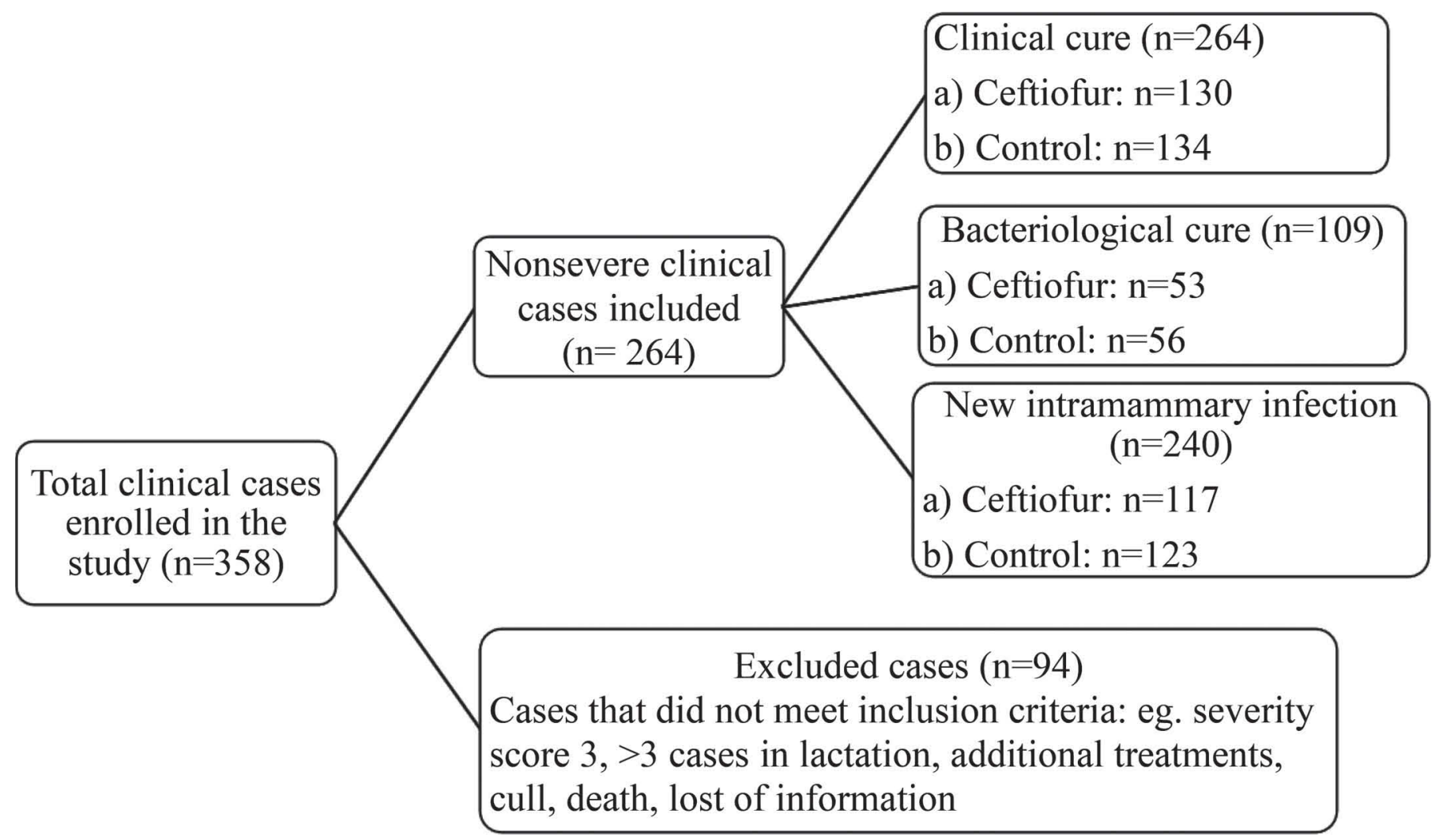

Figure 1. Enrollment of cows to evaluate the efficacy of intramammary ceftiofur hydrochloride for treatment of nonsevere clinical mastitis in dairy cows. 
Table 1. Descriptive results of pretreatment cow level characteristics (mean and SD in parentheses) and severity of clinical mastitis (number of occurrences and percentage in parentheses) according to intramammary treatment group

\begin{tabular}{lccc}
\hline & \multicolumn{2}{c}{ Treatment } \\
\cline { 2 - 3 } Item & Ceftiofur $^{1}(\mathrm{n}=130)$ & Control $^{2}(\mathrm{n}=134)$ & P-value \\
\hline Cow characteristics, $\mathrm{n}(\mathrm{SD})$ & $1.8(0.4)$ & $1.7(0.5)$ & 0.827 \\
$\quad$ Lactation number & $165.3(116.0)$ & $199.5(144.2)$ & 0.187 \\
DIM $^{3}$ & $4.3(2.4)$ & $4.4(2.2)$ & 0.930 \\
SCC linear score $_{\text {Clinical severity, }}^{4}(\%)$ & $85(48.6)$ & $90(51.4)$ & 0.505 \\
Mild (n= 175) & $45(50.5)$ & $44(49.5)$ & 0.786 \\
Moderate $(\mathrm{n}=89)$ & & & \\
\hline
\end{tabular}

${ }^{1}$ Ceftiofur hydrochloride, $125 \mathrm{mg}$.

${ }^{2}$ Control: tetracycline $200 \mathrm{mg}+$ neomycin $250 \mathrm{mg}+$ bacitracin $28 \mathrm{mg}+$ prednisolone $10 \mathrm{mg}$.

${ }^{3}$ Days in milk at the day of clinical mastitis occurrence.

${ }^{4}$ Linear score of SCC measured at the last milk recording before clinical mastitis.

where (cure; NIMI) was the clinical and bacteriological cure (yes or no) and new intramammary infection (NIMI) proportion; parity was the number of lactation of enrolled cows (primiparous and multiparous); DIM was the days in milk at the time of occurrence of CM, as a continuous variable; quarter position (front or hind); lnSCC was the linear score of SCC before the occurrence of CM; severity score (mild or moderate); and treatment (ceftiofur or control).

For evaluation of the effect of bacterial group (grampositive vs. gram-negative), a second model (model 2) was used. In model 2 , the effect of bacterial group and its interaction with treatment was included in the previous model.

Nonsignificant variables were excluded from the model using a stepwise-backward analysis. For both models, analyses were carried out using PROC GLIMMIX of SAS, version 9.2 (SAS Institute Inc.).

\section{RESULTS}

\section{Descriptive Results}

Clinical mastitis cases from 11 commercial dairy farms located in 3 States of Brazil (São Paulo, $\mathrm{n}=2$; Minas Gerais, $\mathrm{n}=2$; and Parana, $\mathrm{n}=7$ ) were enrolled in this study. In total, $358 \mathrm{CM}$ cases met the enrollment criteria for the study. After evaluating data for the total clinical cases, 94 enrolled cases (48 in the ceftiofur treatment group and 46 in control treatment group) did not meet posttreatment admission criteria (Figure 1). The main reasons for exclusion of cases postadmission in the ceftiofur treatment group were evolution of the case to severe mastitis $(\mathrm{n}=14)$, death or culling of the cow $(\mathrm{n}=13)$, additional antimicrobial systemic treatment for reasons other than mastitis $(\mathrm{n}=9)$, mastitis in more than one quarter $(\mathrm{n}=6)$, yeast isolation $(\mathrm{n}=$ 2 ), cows presenting $>3 \mathrm{CM}$ cases in the current lactation $(\mathrm{n}=2)$, and failure to follow the correct treatment protocol $(\mathrm{n}=2)$. On the other hand, for cows in the control group the main reasons for exclusion of cases postadmission were evolution of the case to severe mastitis $(\mathrm{n}=8)$, death or culling of the cow (n $=10$ ), additional antimicrobial systemic treatment for reasons other than mastitis $(\mathrm{n}=9)$, mastitis in more than one quarter $(n=6)$, yeast isolation $(n=6)$, cows presenting $>3 \mathrm{CM}$ cases in the current lactation $(\mathrm{n}=$ $4)$, contamination of pretreatment sample $(\mathrm{n}=2)$, and failure to follow the correct treatment protocol $(\mathrm{n}=1)$. Therefore, a total of 264 cases were eligible for statistical analysis in this study. At the onset of treatments, no significant difference was present between groups in relation to lactation number, DIM, pretreatment cow SCC linear score, and clinical severity score (Table 1).

A total of $175(66.3 \%)$ of clinical cases were considered mild and $89(33.7 \%)$ were moderate. Of a total of 264 eligible quarters with nonsevere CM, 130 (49.2\%) were treated with ceftiofur and $134(50.8 \%)$ were treated with the control (Table 1).

\section{Pretreatment Bacteriological Identification}

The frequency of bacteria isolation in the pretreatment milk sample was not different between the treatment groups. Fifty percent $(\mathrm{n}=132)$ of all nonsevere clinical cases had no microbial growth (negative-culture) after $48 \mathrm{~h}$ of incubation. A total of 105 isolates $(39.8 \%)$ were gram-positive, whereas 27 isolates $(10.2 \%)$ were gramnegative bacteria. Streptococcus agalactiae was the most frequently isolated gram-positive mastitis pathogen (n $=24 ; 9.1 \%)$, followed by Staphylococcus aureus $(\mathrm{n}=$ $20 ; 7.6 \%)$ and CNS $(\mathrm{n}=20 ; 7.6 \%)$. Klebsiella spp. $(\mathrm{n}=$ 
Table 2. Frequency of bacteriological culture results at the time of detection of nonsevere clinical mastitis, and the intramammary treatment regimen (ceftiofur vs. control) to which the cases were submitted

\begin{tabular}{|c|c|c|c|c|c|c|}
\hline \multirow[b]{2}{*}{ IMI status at detection } & \multicolumn{2}{|c|}{ Ceftiofur $^{1}$} & \multicolumn{2}{|c|}{ Control $^{2}$} & \multicolumn{2}{|c|}{ Total } \\
\hline & $\mathrm{n}$ & $\%$ & $\mathrm{n}$ & $\%$ & $\mathrm{n}$ & $\%$ \\
\hline No growth & 68 & 25.8 & 64 & 24.2 & 132 & 50.0 \\
\hline Gram-positive & 45 & 17.0 & 60 & 22.7 & 105 & 39.8 \\
\hline Streptococci $^{3}$ & 28 & 10.6 & 29 & 11.0 & 57 & 21.6 \\
\hline Streptococcus agalactiae & 16 & 6.1 & 8 & 3.0 & 24 & 9.1 \\
\hline Streptococcus uberis & 8 & 3.0 & 8 & 3.0 & 16 & 6.1 \\
\hline Streptococcus dysgalactiae & 3 & 1.1 & 7 & 2.7 & 10 & 3.8 \\
\hline Enterococcus spp. & 1 & 0.4 & 4 & 1.5 & 5 & 1.9 \\
\hline Streptococcus spp. & 0 & 0.0 & 2 & 0.8 & 2 & 0.8 \\
\hline Staphylococci ${ }^{4}$ & 12 & 4.5 & 28 & 10.6 & 40 & 15.2 \\
\hline Staphylococcus aureus & 6 & 2.3 & 14 & 5.3 & 20 & 7.6 \\
\hline CNS & 6 & 2.3 & 14 & 5.3 & 20 & 7.6 \\
\hline Corynebacterium spp. & 5 & 1.9 & 3 & 1.1 & 8 & 3.0 \\
\hline Gram-negative & 17 & 6.4 & 10 & 3.8 & 27 & 10.2 \\
\hline Escherichia coli & 8 & 3.0 & 3 & 1.1 & 11 & 4.2 \\
\hline Klebsiella spp. & 7 & 2.7 & 5 & 1.9 & 12 & 4.5 \\
\hline Other gram-negative $^{5}$ & 2 & 0.8 & 2 & 0.8 & 4 & 1.5 \\
\hline Total & 130 & 49.2 & 134 & 50.8 & 264 & 100 \\
\hline
\end{tabular}

${ }^{1}$ Ceftiofur hydrochloride, $125 \mathrm{mg}$.

${ }^{2}$ Control: tetracycline $200 \mathrm{mg}+$ neomycin $250 \mathrm{mg}+$ bacitracin $28 \mathrm{mg}+$ prednisolone $10 \mathrm{mg}$.

${ }^{3}$ Streptococci: Strep. agalactiae, Strep. uberis, Strep. dysgalactiae, Streptococcus spp., and Enterococcus spp.

${ }^{4}$ Staphylococcus aureus and CNS.

${ }^{5}$ Pseudomonas spp. and Enterobacter spp.

$12 ; 4.5 \%)$ and Escherichia coli $(\mathrm{n}=11 ; 4.2 \%)$ were the most isolated gram-negative bacteria (Table 2).

\section{Bacteriological, Clinical Cure, and New IMI}

Logistic regression results for clinical and bacteriological cure, and new infection outcomes (model 1) are presented in Table 3. No significant differences were observed between treatments regarding the overall clinical cure $[$ odds ratio $(\mathbf{O R})=1.28 ; 95 \% \mathrm{CI}=0.711-2.303$; $P=0.409]$, bacteriological cure $(\mathrm{OR}=1.222 ; 95 \%$ CI
$=0.470-3.180 ; P=0.678)$, and new IMI $(\mathrm{OR}=0.774$ $95 \% \mathrm{CI}=0.399-1.501 ; P=0.446)$. For clinical cure, the only significant effect was the number of clinical cases before the onset of treatment $(\mathrm{OR}=0.513 ; 95 \%$ CI: $0.415-0.863 ; P=0.006$; Table 3$)$.

The overall clinical cure was $0.79( \pm 0.06)$ for ceftiofur-treated cows and $0.74( \pm 0.06)$ for control-treated cows, whereas the overall bacteriological cure was 0.79 $( \pm 0.06)$ for ceftiofur-treated cows and $0.76( \pm 0.07)$ for control-treated cows. Furthermore, the overall results of new IMI was $0.10( \pm 0.04)$ for cows treated with

Table 3. Mixed logistic regression model results for clinical and bacteriological cure, and new IMI of nonsevere clinical mastitis (herd was included as a random effect) ${ }^{1}$

\begin{tabular}{|c|c|c|c|c|c|c|}
\hline Effect & Description & Estimate & SE & $P$-value & Odds ratio & $95 \% \mathrm{CI}$ \\
\hline Intercept & \multirow[b]{2}{*}{ Ceftiofur vs. control } & 1.470 & 0.370 & 0.003 & & \\
\hline Treatment & & 0.246 & 0.298 & 0.409 & 1.28 & $0.711-2.303$ \\
\hline \multicolumn{7}{|l|}{ Bacteriological cure } \\
\hline Intercept & \multirow[b]{2}{*}{ Ceftiofur vs. control } & 1.084 & 0.454 & 0.038 & & \\
\hline Treatment & & 0.200 & 0.482 & 0.678 & 1.222 & $0.470-3.18$ \\
\hline Treatment & \multirow[t]{2}{*}{ Ceftiofur vs. control } & -0.061 & 0.380 & 0.872 & 0.941 & $0.445-1.989$ \\
\hline Number clinical $^{2}$ & & 0.127 & 0.241 & 0.600 & 1.135 & $0.705-1.827$ \\
\hline
\end{tabular}

${ }^{1}$ Treatment regimen: ceftiofur hydrochloride $(125 \mathrm{mg}$ ) versus control (tetracycline $200 \mathrm{mg}+$ neomycin $250 \mathrm{mg}+$ bacitracin $28 \mathrm{mg}+$ prednisolone $10 \mathrm{mg})$.

${ }^{2}$ Number of clinical cases before onset of treatment. 


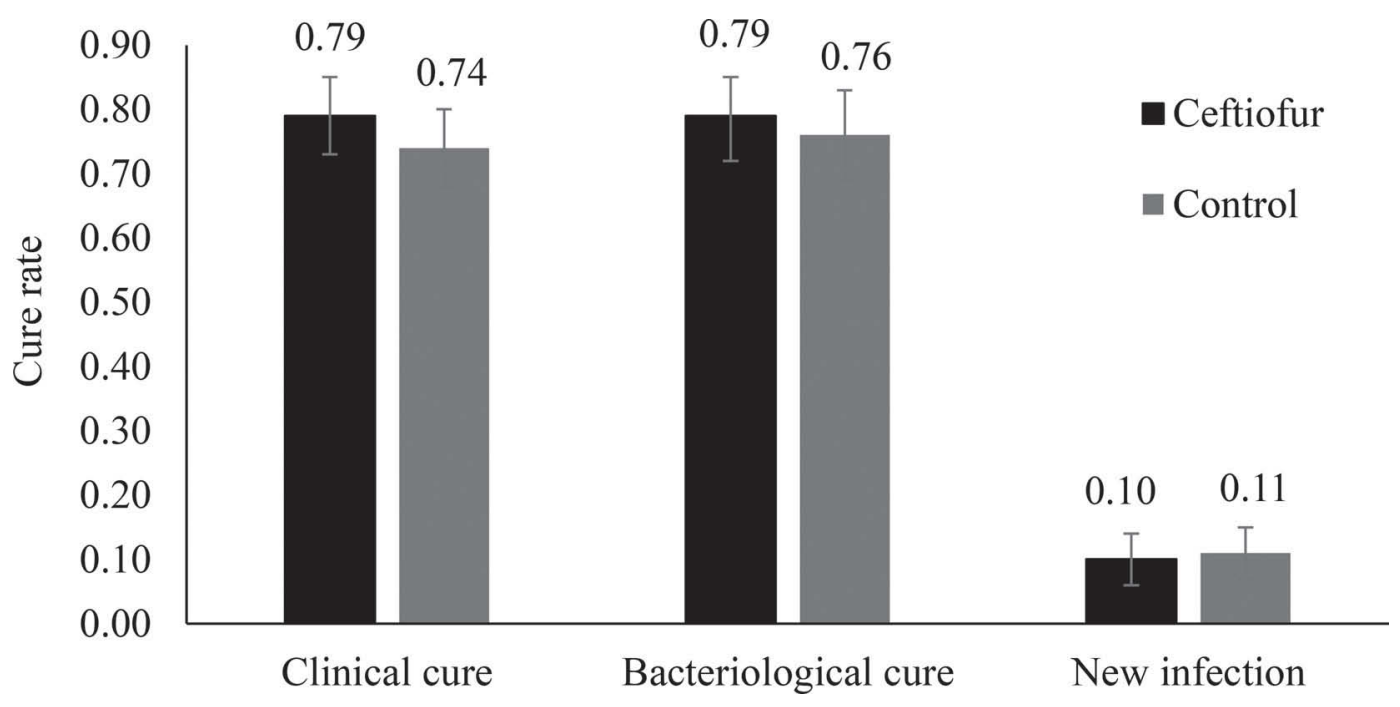

Figure 2. Least squares means and standard error (bars) of overall clinical cure, treatment failure, bacteriological cure, and new infection of nonsevere clinical mastitis in dairy cows, according to intramammary treatment (ceftiofur hydrochloride, $125 \mathrm{mg}$; control: tetracycline $200 \mathrm{mg}$ + neomycin $250 \mathrm{mg}+$ bacitracin $28 \mathrm{mg}+$ prednisolone $10 \mathrm{mg}$ ).

ceftiofur and $0.11( \pm 0.04)$ for cows treated with control (Figure 2). All the estimates are least squares means obtained from the regression models.

Also, there was no effect of treatments when the bacterial group (gram-positive vs. gram-negative) was included in the model on the clinical and bacteriological cure, treatment failure, and new IMI (model 2). Clinical cure was observed for 192 out of 264 enrolled cases (0.73). Cows treated with ceftiofur had clinical cure of 0.75 , and cows in the control group had 0.71 of clinical cure (Table 4). Overall clinical cure was 0.76 for quarters with no growth at pretreatment culturing (100 quarters with negative-culture out of 132 quarters cultured), 0.70 for gram-negative bacteria (19 out of 27 ), and 0.70 (73 out of 105) for gram-positive bacteria.

Bacteriological cure was observed for 83 out of 109 evaluated cases (0.76). Similarly, for clinical cure, no difference was found between the 2 treatments on the bacteriological cure when the bacterial group was included in the model. The bacteriological cure for cows

Table 4. Effect of intramammary treatment (ceftiofur vs. control) on the clinical and bacteriological cure of nonsevere clinical mastitis

\begin{tabular}{|c|c|c|c|c|}
\hline \multirow[b]{2}{*}{ Pathogen } & \multicolumn{2}{|c|}{ Clinical cure ${ }^{1}$} & \multicolumn{2}{|c|}{ Bacteriological cure $^{1}$} \\
\hline & Ceftiofur $^{2}$ & Control $^{3}$ & Ceftiofur $^{2}$ & Control $^{3}$ \\
\hline No growth & $0.79(54 / 68)$ & $0.72(46 / 64)$ & - & - \\
\hline Gram-negative & $0.82(14 / 17)$ & $0.50(5 / 10)$ & $0.93(14 / 15)$ & $0.75(6 / 8)$ \\
\hline Escherichia coli & $1.00(8 / 8)$ & $1.00(3 / 3)$ & $1.00(8 / 8)$ & $1.00(3 / 3)$ \\
\hline Klebsiella spp. & $0.57(4 / 7)$ & $0.20(1 / 5)$ & $0.80(4 / 5)$ & $0.67(2 / 3)$ \\
\hline Enterobacter spp. & $1.00(1 / 1)$ & & $1.00(1 / 1)$ & \\
\hline Pseudomonas spp. & $1.00(1 / 1)$ & $0.50(1 / 2)$ & $1.00(1 / 1)$ & $0.50(1 / 2)$ \\
\hline Gram-positive & $0.64(29 / 45)$ & $0.73(44 / 60)$ & $0.71(27 / 38)$ & $0.75(36 / 48)$ \\
\hline Environmental streptococci & $0.92(11 / 12)$ & $0.71(15 / 21)$ & $0.82(9 / 11)$ & $0.94(15 / 16)$ \\
\hline Strep. uberis & $0.87(7 / 8)$ & $0.87(7 / 8)$ & $0.71(5 / 7)$ & $0.87(7 / 8)$ \\
\hline Strep. dysgalactiae & $1.00(3 / 3)$ & $0.43(3 / 7)$ & $1.00(3 / 3)$ & $1.00(3 / 3)$ \\
\hline Streptococcus spp. & - & $0.50(1 / 2)$ & - & $1.00(2 / 2)$ \\
\hline Enterococcus spp. & $1.00(1 / 1)$ & $1.00(4 / 4)$ & $1.00(1 / 1)$ & $1.00(3 / 3)$ \\
\hline Strep. agalactiae & $0.31(5 / 16)$ & $0.50(4 / 8)$ & $0.57(8 / 14)$ & $0.62(5 / 8)$ \\
\hline Staph. aureus & $0.83(5 / 6)$ & $0.79(11 / 14)$ & $0.75(3 / 4)$ & $0.70(7 / 10)$ \\
\hline CNS & $0.83(5 / 6)$ & $0.93(13 / 14)$ & $0.83(5 / 6)$ & $0.58(7 / 12)$ \\
\hline Corynebacterium spp. & $0.60(3 / 5)$ & $0.34(1 / 3)$ & $0.67(2 / 3)$ & $1.00(2 / 2)$ \\
\hline Total & $0.75(97 / 130)$ & $0.71(95 / 134)$ & $0.77(41 / 53)$ & $0.75(42 / 56)$ \\
\hline
\end{tabular}

${ }^{1}$ Number of cured cases divided by number of cases is presented in parentheses.

${ }^{2}$ Ceftiofur hydrochloride, $125 \mathrm{mg}$.

${ }^{3}$ Control = tetracycline $200 \mathrm{mg}+$ neomycin $250 \mathrm{mg}+$ bacitracin $28 \mathrm{mg}+$ prednisolone $10 \mathrm{mg}$. 
Table 5. Frequency (absolute and relative) of pathogens causing new IMI according to treatment regimens

\begin{tabular}{|c|c|c|c|c|c|c|}
\hline \multirow[b]{3}{*}{ Pathogen } & \multicolumn{4}{|c|}{ Treatment } & \multirow{2}{*}{\multicolumn{2}{|c|}{$\begin{array}{c}\text { Total } \\
(\mathrm{n}=240)\end{array}$}} \\
\hline & \multicolumn{2}{|c|}{ Ceftiofur $^{1}(\mathrm{n}=117)$} & \multicolumn{2}{|c|}{ Control $^{2}(\mathrm{n}=123)$} & & \\
\hline & $\mathrm{n}$ & $\%$ & $\mathrm{n}$ & $\%$ & $\mathrm{n}$ & $\%$ \\
\hline Gram-negative & 2 & 1.71 & 1 & 0.81 & 3 & 1.25 \\
\hline Escherichia coli & 0 & 0.00 & 1 & 0.81 & 1 & 0.42 \\
\hline Klebsiella spp. & 1 & 0.85 & 0 & 0.00 & 1 & 0.42 \\
\hline Pseudomonas spp. & 1 & 0.85 & 0 & 0.00 & 1 & 0.42 \\
\hline Gram-positive & 13 & 11.11 & 18 & 14.63 & 31 & 12.92 \\
\hline $\mathrm{CNS}^{1}$ & 4 & 3.42 & 7 & 5.69 & 11 & 4.58 \\
\hline Streptococcus uberis & 3 & 2.56 & 5 & 4.07 & 8 & 3.33 \\
\hline Staphylococcus aureus & 6 & 5.13 & 1 & 0.81 & 7 & 2.92 \\
\hline Streptococcus agalactiae & 0 & 0.00 & 2 & 1.63 & 2 & 0.83 \\
\hline Corynebacterium spp. & 0 & 0.00 & 2 & 1.63 & 2 & 0.83 \\
\hline Enterococcus spp. & 0 & 0.00 & 1 & 0.81 & 1 & 0.42 \\
\hline Other & 2 & 1.71 & 0 & 0.00 & 2 & 0.83 \\
\hline Yeast & 1 & 0.85 & 0 & 0.00 & 1 & 0.42 \\
\hline Prototheca spp. & 1 & 0.85 & 0 & 0.00 & 1 & 0.42 \\
\hline Total & 17 & 14.53 & 19 & 15.45 & 36 & 15.00 \\
\hline
\end{tabular}

${ }^{1}$ Ceftiofur hydrochloride, $125 \mathrm{mg}$.

${ }^{2}$ Control $=$ tetracycline $200 \mathrm{mg}+$ neomycin $250 \mathrm{mg}+$ bacitracin $28 \mathrm{mg}+$ prednisolone $10 \mathrm{mg}$.

treated with ceftiofur was 0.77 , whereas cows treated with the control therapy had a bacteriological cure of 0.75 . Overall least squares means for bacteriological cure were 0.87 for gram-negative bacteria (20 quarters with isolation of gram-negative bacteria out of 23 quarters cultured), and 0.73 for gram-positive bacteria (63 out of 86 ; Table 4 ).

A total of 240 out of 264 mammary quarters were evaluated for new IMI (117 in the ceftiofur treatment regimen, and 123 in the control treatment regimen). Twenty-four cases were excluded from the analysis of new IMI due to lack of sample collection or loss of data. No significant difference of new IMI was observed between quarters treated with ceftiofur and quarters treated with the control treatment. Mammary quarters treated with ceftiofur had 17 cases $(14.53 \%)$ of new intramammary infection, whereas quarters treated with control treatment regimens had 19 cases (15.45\%; Table 5).

Gram-positive bacteria were the most isolated pathogens of new IMI $(12.92 \%$; $=31)$, whereas gram-negative bacteria were isolated in only $1.25 \%(\mathrm{n}=3)$. Both yeast $(\mathrm{n}=1)$ and Prototheca $\mathrm{spp} .(\mathrm{n}=1)$ accounted for $0.42 \%$ of new IMI (both in the ceftiofur treatment regimen). Staphylococcus aureus was the most frequent cause of new IMI in quarters treated with ceftiofur $(5.13 \% ; \mathrm{n}=6)$ followed by CNS $(3.42 \% ; \mathrm{n}=4)$. Coagulase negative staphylococci were the most frequent isolated pathogens of the new intramammary infection cases of the control group $(5.69 \%, \mathrm{n}=7)$, followed by Streptococcus uberis (4.07\%; $\mathrm{n}=5$; Table 5).

\section{DISCUSSION}

This study compared 2 intramammary protocols for treatment of nonsevere CM: one protocol containing a third-generation cephalosporin in its formulation (ceftiofur hydrochloride), and a positive control with a combination of antibiotics (tetracycline + neomycin + bacitracin) and prednisolone. Both products were formulated with the objective of ensuring a broad spectrum of activity against mastitis-causing bacteria. The 2 treatment groups had high clinical and bacteriological cure of nonsevere cases of CM, although no difference was observed between groups in relation to these outcomes. In addition, no differences of new IMI proportions were observed between the 2 treatment regimens.

The overall clinical cure was observed for 192 out of 264 enrolled cases (0.73). No effect was found of the clinical severity score on the clinical cure, and therefore, this effect was removed from the final logistic regression model. According to Roberson (2012), it is unlikely that the administration of anti-inflammatory drugs would affect the clinical cure of mild and moderate clinical cases. Cows treated with ceftiofur showed a clinical cure of 0.79 , whereas cows treated with the control therapy presented 0.74 of clinical cure. The clinical cure results observed in our study were slightly higher than observed by Schukken et al. (2013), which reported a clinical cure of 0.62 for nonsevere CM cases after 5 intramammary infusions of ceftiofur. In another study from the same research group, the clinical cure 
was 0.54 for nonsevere $\mathrm{CM}$ caused by gram-negative bacteria after a treatment regimen with 5 intramammary infusions of ceftiofur hydrochloride (Schukken et al., 2011). On the other hand, the clinical cure observed in our study was lower than observed in the study of Truchetti et al. (2014), which reported a clinical cure of 0.89 for both therapy regimens using 2 or 8 intramammary infusions of ceftiofur.

A high bacteriological cure was also observed in this study although no difference was observed between treatment groups. The overall bacteriological cure of our study was 0.76 ( 83 out of $109 \mathrm{CM}$ cases), estimated at 0.79 for ceftiofur-treated cases and 0.76 for controltreated cases. The bacteriological cure observed for ceftiofur-treated cases in our study was higher than observed in other studies, in which a variation of the bacteriological cure was 32 to $77 \%$ reported (PinzónSánchez et al., 2011; Schukken et al., 2011, 2013; Truchetti et al., 2014). Moreover, when ceftiofur was used for treatment of subclinical mastitis in lactating dairy cows the bacteriological cure was also lower than observed in our study. The efficacy of ceftiofur therapy against all naturally occurring subclinical IMI was $38.8,53.7$, and $65.8 \%$ for the 2-, 5-, and 8-d ceftiofur treatment regimens, respectively (Oliver et al., 2004a). The variation in the clinical and bacteriological cure of nonsevere CM observed between studies may be attributed to differences in study design, duration of treatment, time of posttreatment sample collection, mastitis causing pathogen, and characteristics at cow level, as individual cow SCC before treatment, parity, milk yield, and DIM (Bradley and Green, 2009).

In our study, the clinical cure proportion of cows with CM caused by gram-negative pathogens was similar in ceftiofur-treated cases compared with control-treated cases, estimated at 0.82 (14 out of 17 cases) and 0.50 (5 out of 10), respectively. Moreover, the bacteriological cure observed in our study showed a similar trend of the clinical cure outcome, with ceftiofur- and controltreated cases presenting 0.93 and 0.75 of bacterial cure, respectively. Schukken et al. (2013), comparing a first-generation with a third-generation cephalosporin, reported no difference of treatment regimens for grampositive bacteria ( 0.67 for ceftiofur vs. 0.68 for cephapirin), but the difference of bacteriological cure was greater for gram-negative bacteria (0.79 for ceftiofur vs. 0.50 for cephapirin). It can be suggested that the low frequency of isolation of gram-negative pathogens (total of 27 cases) resulted in insufficient number of CM cases to detect a statistical difference between the 2 treatment regimens in our study. Contagious pathogens are still an issue in Brazilian dairy herds, which could also be observed by the high prevalence of Streptococ- cus agalactiae (overall of 9.1\%) and Staphylococcus aureus $(7.6 \%)$ in this study in comparison with the overall isolation of gram-negative bacteria (10.2\%).

The number of clinical cases identified before the onset of treatment had a significant effect on the clinical cure of cows in this study. The odds of clinical cure were reduced by 0.513 when a cow had one case of $\mathrm{CM}$ that occurred before the onset of treatment in this study. Previous studies reported that cows that experienced previous cases of mastitis had lower odds of cure than cows with no history of CM (Hektoen et al., 2004; Pinzón-Sánchez et al., 2011). Although a significant effect of the number of clinical cases before the onset of treatment was observed on the clinical cure, the same effect was not observed for bacteriological cure. In contrast, one study reported that cows that experienced $\mathrm{CM}$ for the first time in the lactation were 7 times more likely to have bacteriological cure compared with cows that had previous cases of CM during the lactation (Pinzón-Sánchez and Ruegg, 2011). Only cows treated with ceftiofur by the intramammary route were evaluated in that study.

A total of 36 out of 240 mammary quarters (15\%) presented new IMI in this study, and also, no difference was observed between treatment regimens. In a study evaluating the efficacy of intramammary ceftiofur therapy by comparison of 2 treatment regimens ( 8 vs. 2 d), $10 \%$ of evaluated cows showed new IMI, but no difference was observed between treated groups (Truchetti et al., 2014). The most prevalent pathogens causing new IMI in this study were CNS and Streptococcus uberis, which are, respectively, considered opportunistic and environmental pathogens that cause IMI mainly during cows' immunosuppression (Taponen and Pyörälä, 2009; Abureema et al., 2014).

Our study evaluated the efficacy of 2 existing antibiotics that are on the market for treatment of IMI. The results of this study indicated that both formulations presented similar and high clinical and bacteriological cure of nonsevere naturally occurring $\mathrm{CM}$ cases. It can be argued that the comparison of a given antibiotic with another commercially available product is not as accurate as compared with a negative control (Roberson, 2012). However, the results of this study may provide better support for veterinary clinicians and farm personnel for day-to-day decision-making regarding the therapy of CM.

\section{CONCLUSIONS}

This study evaluated 2 commercially available antibiotics with broad spectrum used to treat IMI. We conclude that a regimen using ceftiofur hydrochloride 
for treatment of nonsevere CM has similar efficacy as a treatment regimen with a combination of antibiotics (tetracycline + neomycin + bacitracin) and prednisolone.

\section{ACKNOWLEDGMENTS}

We are grateful to José Garcia Franchini and Lucineia Mestieri (Qualileite Milk Quality Laboratory, School of Veterinary Medicine and Animal Science, University of São Paulo, Pirassununga, Brazil) for their assistance with laboratory analysis. We also acknowledge Zoetis Animal Health (São Paulo, Brazil) for providing financial support of this study.

\section{REFERENCES}

Abureema, S., P. Smooker, J. Malmo, and M. Deighton. 2014. Molecular epidemiology of recurrent clinical mastitis due to Streptococcus uberis: Evidence of both an environmental source and recurring infection with the same strain. J. Dairy Sci. 97:285-290.

Bradley, A. J., and M. J. Green. 2009. Factors affecting cure when treating bovine clinical mastitis with cephalosporin-based intramammary preparations. J. Dairy Sci. 92:1941-1953.

Gruet, P., P. Maincent, X. Berthelot, and V. Kaltsatos. 2001. Bovine mastitis and intramammary drug delivery: Review and perspectives. Adv. Drug Deliv. Rev. 50:245-259.

Halasa, T., K. Huijps, O. Osteras, and H. Hogeveen. 2007. Economic effects of bovine mastitis and mastitis management: A review. Vet. Q. 29:18-31.

Heikkilä, A. M., J. I. Nousiainen, and S. Pyörälä. 2012. Costs of clinical mastitis with special reference to premature culling. J. Dairy Sci. 95:139-150.

Hektoen, L., S. A. Odegaard, T. Loken, and S. Larsen. 2004. Evaluation of stratification factors and score-scales in clinical trials of treatment of clinical mastitis in dairy cows. J. Vet. Med. A Physiol. Pathol. Clin. Med. 51:196-202.

International Dairy Federation (IDF). 1999. Suggested interpretation of mastitis terminology. Bull. Int. Dairy Fed. 338:3-26.

Lago, A., S. M. Godden, R. Bey, P. L. Ruegg, and K. Leslie. 2011. The selective treatment of clinical mastitis based on on-farm culture results: I. Effects on antibiotic use, milk withholding time, and short-term clinical and bacteriological outcomes. J. Dairy Sci. 94:4441-4456.
Oliveira, L., and P. L. Ruegg. 2014. Treatments of clinical mastitis occurring in cows on 51 large dairy herds in Wisconsin. J. Dairy Sci. 97:5426-5436.

Oliver, S. P., B. E. Gillespie, S. J. Headrick, H. Moorehead, P. Lunn, H. H. Dowlen, D. L. Johnson, K. C. Lamar, S. T. Chester, and W. M. Moseley. 2004a. Efficacy of extended ceftiofur intramammary therapy for treatment of subclinical mastitis in lactating dairy cows. J. Dairy Sci. 87:2393-2400.

Oliver, S. P., R. N. Gonzalez, J. S. Hogan, B. M. Jayarao, and W. E. Owens, ed. 2004b. Microbiological Procedures for the Diagnosis of Bovine Udder Infection and Determination of Milk Quality. 4th ed. National Mastitis Council Inc., Verona, WI.

Oliver, S. P., and S. E. Murinda. 2012. Antimicrobial resistance of mastitis pathogens. Vet. Clin. North Am. Food Anim. Pract. $28: 165-185$.

Pinzón-Sánchez, C., V. E. Cabrera, and P. L. Ruegg. 2011. Decision tree analysis of treatment strategies for mild and moderate cases of clinical mastitis occurring in early lactation. J. Dairy Sci. 94:1873-1892.

Pinzón-Sánchez, C., and P. L. Ruegg. 2011. Risk factors associated with short-term post-treatment. J. Dairy Sci. 94:3397-3410.

Roberson, J. R. 2012. Treatment of clinical mastitis. Vet. Clin. North Am. Food Anim. Pract. 28:271-288.

Ruegg, P. L., L. Oliveira, W. Jin, and O. Okwumabua. 2015. Phenotypic antimicrobial susceptibility and occurrence of selected resistance genes in Gram-positive mastitis pathogens isolated from Wisconsin dairy cows. J. Dairy Sci. 98:4521-4534.

Schukken, Y. H., G. J. Bennett, M. J. Zurakowski, H. L. Sharkey, B. J. Rauch, M. J. Thomas, B. Ceglowski, R. L. Saltman, N. Belomestnykh, and R. N. Zadoks. 2011. Randomized clinical trial to evaluate the efficacy of a 5-day ceftiofur hydrochloride intramammary treatment on nonsevere gram-negative clinical mastitis. J. Dairy Sci. 94:6203-6215.

Schukken, Y. H., M. J. Zurakowski, B. J. Rauch, B. Gross, L. L. Tikofsky, and F. L. Welcome. 2013. Noninferiority trial comparing a first-generation cephalosporin with a third-generation cephalosporin in the treatment of nonsevere clinical mastitis in dairy cows. J. Dairy Sci. 96:6763-6774.

Taponen, S., and S. Pyörälä. 2009. Coagulase-negative staphylococci as cause of bovine mastitis - Not so different from Staphylococcus aureus? Vet. Microbiol. 134:29-36.

Truchetti, G., E. Bouchard, L. DesCôteaux, D. Scholl, and J. P. Roy. 2014. Efficacy of extended intramammary ceftiofur therapy against mild to moderate clinical mastitis in Holstein dairy cows: A randomized trial. Can. J. Vet. Res. 78:31-37.

Wenz, J. R., F. B. Garry, and G. M. Barrington. 2006. Comparison of disease severity scoring systems for dairy cattle with acute coliform mastitis. J. Am. Vet. Med. Assoc. 229:259-262. 